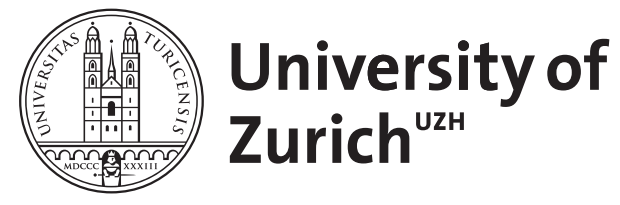

Zurich Open Repository and Archive

University of Zurich

University Library

Strickhofstrasse 39

CH-8057 Zurich

www.zora.uzh.ch

Year: 2017

Bevacizumab for the treatment of Osler's disease - A note of caution

Stickel, Felix ; Z'graggen, Kaspar

DOI: https://doi.org/10.1111/liv.13361

Posted at the Zurich Open Repository and Archive, University of Zurich

ZORA URL: https://doi.org/10.5167/uzh-144847

Journal Article

Accepted Version

Originally published at:

Stickel, Felix; Z'graggen, Kaspar (2017). Bevacizumab for the treatment of Osler's disease - A note of caution. Liver International, 37(6):927-928.

DOI: https://doi.org/10.1111/liv.13361 


\title{
Bevacizumab for the treatment of Osler's disease - A note of caution
}

Short title: Bevacizumab for Osler's disease

\author{
Felix Stickel $^{1,2}$, Kaspar Z'graggen $^{3}$ \\ ${ }^{1}$ Hepatology Unit, Hirslanden Clinic Beau-Site, Bern \\ \& \\ ${ }^{2}$ Department of Gastroenterology and Hepatology, University Hospital of Zürich, \\ Switzerland \\ ${ }^{3}$ Centre of Visceral Surgery, Clinic Beau-Site Hirslanden, Bern
}

Key words: hereditary haemorrhagic teleangiectasia, angiogenesis, portal vein thrombosis, cholestasis

Word count: 415

Figures: 1

Tables: 0

Conflict of interest: None

Financial support and funding: The present work was not been funded specifically and represents an extraction of clinical work

Abbreviations used in the text: HCC, hepatocellular carcinoma; HHT, hereditary hemorrhagic teleangiectasia; LT, liver transplantation; VM, vascular malformation 


\section{Corresponding author}

Felix Stickel, MD

Hepatology Unit

Hirslanden Clinic Beau-Site

Schänzlihalde 11, 3013 Bern

Switzerland

Tel: +4131335 7817; Fax: +41313353519

felix.stickel@uzh.ch; felix.stickel@hirslanden.ch

\section{Ethics}

No ethics committee approval has been obtained for this study since the report represents a single patient experience. However, written informed consent from the patient according to the Journal's guidelines has been retrieved in which the patient approves publication of data anonymously. 


\section{To the Editor,}

Three reports recently presented clinical data and comments on a 65-year old woman in whom hereditary haemorrhagic teleangiectasia (HHT; Osler's disease) and hepatocellular carcinoma (HCC) coincided, leading to listing for liver transplantation (LT) (1-3). Consensus existed on the usefulness of LT in patients with HHT, particularly when complicated by HCC, but there was debate over the right timing for LT in such patients who are usually well besides the complications of vascular malformations (VM). The reported case was complicated by the fact that transarterial chemoembolization for HCC is contraindicated in HHT due to a high incidence of abscesses. Hence, therapeutic interventions that override the transplant list waiting time are needed.

Dubuis-Girod and Buscarini (3) advocate the use of bevacizumab, an endothelial growth factor antibody approved for treating various cancers, as a "bridge-totransplant" measure in patients with $\mathrm{HHT}$ and hepatic VM according to a trial in which 20/24 patients with HHT responded to bevacizumab with improvements of cardiac index (Cl), nose bleeds, and quality of life (4).

We report on a 72-year old female with HHT and VM (type III) with symptoms of high cardiac output, bilateral leg edema, palpitations and cardiac cachexia with a weight loss of $7 \mathrm{~kg} / 11$ months. We started bevacizumab treatment 3 years ago at $5 \mathrm{mg} / \mathrm{kg}$ for 6 applications every other week. Treatment was then very well tolerated and all symptoms subsided. Cardiac output (CO) decreased from $15.3 \mathrm{~L} / \mathrm{min}\left(\mathrm{Cl} 9.5 \mathrm{~L} / \mathrm{min} / \mathrm{m}^{2}\right)$ to $7.0 \mathrm{~L} / \mathrm{min}\left(4.4 \mathrm{~L} / \mathrm{min} / \mathrm{m}^{2}\right)$, and further improved to $6.5 \mathrm{~L} / \mathrm{min}\left(3.9 \mathrm{~L} / \mathrm{min} / \mathrm{m}^{2}\right) 21 / 2$ years after treatment cessation.

However, the patient recently complained about similar symptoms as initially, and CO and $\mathrm{Cl}$ were measured at $9.0 \mathrm{~L} / \mathrm{min}$ and $5.5 \mathrm{~L} / \mathrm{min} / \mathrm{m}^{2}$, respectively. We started a second course with bevacizumab $(5 \mathrm{mg} / \mathrm{kg})$ during which the patient developed acute 
abdominal pain and presented with fever at $39.2^{\circ} \mathrm{C}$, leucocytosis $12.100 / \mathrm{L}$, C-reactive protein $126 \mathrm{mg} / \mathrm{L}$ and mild cholestasis. Computed tomography excluded intestinal perforation, but showed bilateral intrahepatic portal vein thrombosis (figure 1). Upon analgesia, ceftriaxone and nadroparin symptoms improved rapidly, and treatment with phenprocoumon was started.

Our case confirms that bevacizumab can markedly improve cardiac symptoms and function in patients with HHT and offers treatment for those not eligible for LT. However, bevacizumab may cause serious side effects among which deep vein thrombosis has been reported in up to $13 \%$ of treated patients in oncology trials (5). Although thromboembolic events could predominantly be due to the underlying malignancy (6), they should be carefully considered when treating patients with HHT for which bevacizumab is not officially approved and for which experience is still limited to case series.

\section{References}

1. Muller YD, Oppliger R, Breguet R, et al. Hereditary haemorrhagic telangiectasia: to transplant or not to transplant - is there a right time for liver transplantation? Liver Int 2016; 36: 1735-1740.

2. Dupuis-Girod S, Buscarini E. Hereditary hemorrhagic telangiectasia: to transplant or not to transplant? Liver Int 2016; 36: 1741-1744.

3. Sabba C. Hereditary haemorrhagic telangiectasia: to transplant or not to transplant? Liver Int 2016; 36: 1745-1747.

4. Dupuis-Girod S, Ginon I, Saurin JC, et al. Bevacizumab in patients with hereditary hemorrhagic telangiectasia and severe hepatic vascular malformations and high cardiac output. JAMA 2012; 307: 948-55. 
5. Cassidy J, Saltz LB, Giantonio BJ, et al. Effect of bevacizumab in older patients with metastatic colorectal cancer: pooled analysis of four randomized studies. $J$ Cancer Res Clin Oncol 2010; 136: 737-43.

6. Hurwitz HI, Saltz LB, Van Cutsem E, et al. Venous thromboembolic events with chemotherapy plus bevacizumab: a pooled analysis of patients in randomized phase II and III studies. J Clin Oncol 2011; 29: 1757-64.

\section{Legend to}

\section{Figure 1}

CT scan showing bilateral portal vein thrombosis (white arrows). 